\title{
Dvojno njihalo povijesti \\ Filozofija povijesti Pavla Vuk-Pavlovića
}

\author{
Tvrtko Jolić" \\ tjolic@ifzg.hr \\ https://orcid.org/0000-0003-4424-1933
}

\author{
https://doi.org/10.31192/np.18.3.1 \\ UDK: 1Vuk-Pavlović, P. \\ 930.1 \\ Izvorni znanstveni rad / Original scientific paper \\ Primljeno: 23. srpnja 2020. \\ Prihvaćeno: 20. rujna 2020.
}

Vuk-Pavlovićeva filozofija povijesti usko je povezana s njegovim shvaćanjem kulture kao dinamičkog procesa u kojemu se povijesne epohe izmjenjuju ovisno o trenutnoj snazi sukobljenih svjetonazora. Razmatrajući primjere svjetonazorskih sukoba (nominalizam naspram realizma, individualizam naspram kolektivizma, sloboda naspram jednakosti), pokušat ćemo doći do boljeg razumijevanja povijesnog procesa kako ga shvaća Vuk-Pavlović. U radu će se razmotriti uloga koju Vuk-Pavlović pripisuje povijesti i predaji za oblikovanje društvenog života. Iako se ne može reći da je Vuk-Pavlović izložio cjelovito razrađenu teoriju filozofiju povijesti, u radu je pokazano da njegove postavke o naravi povijesnih procesa i čovjekova odnosa prema povijesti pružaju oslonac za dublje razumijevanje dinamike sukoba unutar suvremenih političkih zajednica.

Ključne riječi: filozofija kulture, filozofija povijesti, kultura, Pavao Vuk-Pavlović, povijest.

\section{Uvod}

O filozofiji povijesti Pavla Vuk-Pavlovića nije mnogo pisano. U opsežnoj trosveščanoj Filozofiji historije Predraga Vranickog, u dijelu posvećenom hrvatskim filozofima, njegovo ime se ne spominje. ${ }^{1}$ Stoga vrijednu iznimku čini rad Radomira Videnovića u kojemu autor ukazuje na aktualnost Vuk-Pavlovićevih razmatranja ove tematike. Nastavljajući se na ranije uvide Marije Bride, Vide-

\footnotetext{
* Doc. dr. sc. Tvrtko Jolić, Institut za filozofiju, Ulica grada Vukovara 54, HR-10000 Zagreb.

${ }^{1}$ Predrag VRANICKI, Filozofija historije, 3 sveska, Zagreb, Golden marketing, 2001-2003. U trećem svesku Filozofija historije. Nakon Drugog svjetskog rata, 483-547, nalazi se dio posvećen novijoj hrvatskoj filozofiji povijesti, no Vranicki obrađuje isključivo autore koji su pripadali tzv. zagrebačkoj grupi oko časopisa Praxis.
} 
nović ukazuje da se cjelina Vuk-Pavlovićeve filozofske misli može promatrati kao filozofije kulture. ${ }^{2} \mathrm{U}$ tom kontekstu i Vuk-Pavlovićeva filozofija povijesti proizlazi iz njegovih razmatranja o kulturi, njenim mijenama i napetostima unutar nje. Stoga Videnović ističe »da su u filosofiji Vuk-Pavlovića kulturna gibanja prava, istinska povijest čovjekova, te tako govorimo o filosofiji kulture kao o filosofiji povijesti«. ${ }^{3}$ Oslanjajući se na neke od važnih uvida dosadašnjih istraživanja Vuk-Pavlovićeve filozofije povijesti, cilj mi je u ovom radu ukazati na dva pristupa kojima se Vuk-Pavlović služi da bi izložio svoja shvaćanja o važnosti povijesti za oblikovanje naših vlastitih života kao i društvenih odnosa u kojima živimo.

Kada govorimo o filozofiji povijesti kao disciplini, ona se može shvatiti dvojako. ${ }^{4}$ Prvi od temeljna dva pristupa filozofiji povijesti, često nazivan i spekulativni, u povijesnim procesima pokušava otkriti neki obrazac ili poredak koji bi dao smisao povijesnim događanjima. Bez takvoga objašnjenja povijesnih procesa, smatraju zagovornici ovoga pristupa, prijeti opasnost da na pojedinačne povijesne događaje gledamo kao na kaotične izolirane incidente u kojima se onda gubi i razumijevanje smisla ljudskoga života i postojanja. Neki od najranijih pokušaja osmišljavanja povijesti u njoj nalaze odraz Božje volje (Augustin, Toma Akvinski), dočim prosvjetiteljski sekularizam na povijest gleda kao na proces stalnog napretka prema sve savršenijim oblicima ljudskog postojanja i organizacije. Druge pak teorije iz ovog spekulativnog pristupa povijesti smatraju da se povijesni obrasci ne odvijaju linearno već da se ponavljaju te tada govorimo o cikličkim teorijama filozofije povijesti.

Za razliku od ovoga spekulativnog pristupa, drugi pristup povijesti filozofskim promišljanjem pokušava otkriti temeljne pojmove i kategorije kojima možemo postići ispravno razumijevanje povijesnih događaja i procesa. Zadaća filozofije povijesti, prema ovome shvaćanju, nije otkrivanje nekog obrasca koji je u podlozi povijesnih kretanja već istraživanje načina na koji uopće možemo pristupiti objašnjenju povijesnih procesa. U ovomu se radu pokazuje kako se Vuk-Pavlovićeva shvaćanje filozofije povijesti mogu uklopiti u gore navedena dva pristupa razumijevanja povijesti. Pri tome se analizira njegova dva opsegom kraća rada iz različitih faza njegova filozofiranja. To su ogledi pod naslovom »Pogled na kulturnopovijesna smijeranja« u kojemu Vuk-Pavlović izlaže svoje viđenje povijesnih procesa i njihove dinamike, dok $u$ »Značenju povijesne predaje« razmatra odnos u kojemu čovjek stoji naspram povijesti. ${ }^{5}$

\footnotetext{
${ }^{2}$ Marija BRIDA, Pavao Vuk-Pavlović, čovjek i djelo, Zagreb, Institut za filozofiju Sveučilišta u Zagrebu, 1974.

${ }^{3}$ Radomir VIDENOVIĆ, Aktualnost filosofije povijesti Pavla Vuk-Pavlovića, Metodički ogledi, 18 (2011) 2, 105-114.

4 William Henry WALSH, An Introduction to Philosophy of History, Bristol, Thoemmes Press, 1961, 14.

${ }^{5}$ Prethodno objavljene kao zasebne studije sada se nalaze u Pavao VUK-PAVLOVIĆ, Vrednota u svijetu, Biblioteka Sabrana djela Pavla Vuk-Pavlovića, Zagreb, Hrvatsko filozofsko društvo,
} 


\section{Povijest i kultura}

Da bismo bolje razumjeli Vuk-Pavlovićeva shvaćanja povijesti valja prije svega razmotriti što je za njega kultura, koji je njen temelj i njena svrha. Možda ćemo do, za svrhu ovoga rada najkorisnijeg, shvaćanja kulture doći ako pođemo od toga što Vuk-Pavlović smatra svrhom kulture. Za njega je kultura u prvom redu odgovor na izazove i napetosti koje se nužno nameću ljudskom opstanku i djelovanju. Nastojanja da se nadvladaju teškoće koje se isprječuju ljudskom životu i ostvarenju naših planova i ciljeva gradivni su elementi kulture koja za Vuk-Pavlovića čini

»smislonosan sastav i vrijednostan sklop vezan za živu duševnost ljudsku, koji se nagomilan u duhovnim objektivitetima, odnosno dobrima ustrajno ostvaruje, ali se nikad i ne da smatrati konačno završenim «. ${ }^{6}$

To je definicija kulture koja se odmiče od dotad dominantnih shvaćanja kulture kao vanjskih odrednica, kao što je primjerice teorija koju je zastupao Bronisław Malinowski - prema kojemu je kultura dobro organizirano jedinstvo sastavljeno od materijalnih artefakata i sustava običaja. ${ }^{7}$ Vuk-Pavlović snažno inzistira da bitni aspekti kulture počivaju na onomu što bismo mogli označiti unutarnjim odrednicama kulture, a to su smisao i vrijednosti koji izviru iz »žive duševnosti ljudske«, što je karakteristika cjeline Vuk-Pavlovićeva pristupa u filozofiji. U tom je on bliži suvremenim psihološkim pristupima u kulturnoj antropologiji koja se upravo u vrijeme nastajanja Vuk-Pavlovićeve studije ${ }^{8}$ okreće istraživanju domene vrijednosti koja je dotada uvelike bile ostavljana u pozadini etnografskih opisa običaja i institucija pojedinih kultura. ${ }^{9}$

No najsnažniji pečat Vuk-Pavlovićevom shvaćanju kulture, onaj koji je ključan za njegovo shvaćanje prirode povijesti, daje završni dio njegove već navedene definicije kulture $u$ kojemu se naglašava da se kulturu nikada ne može smatrati dovršenom. Kao što se izazovi ljudskom opstanku stalno mijenjaju tako je i kultura u stalnoj mijeni prezentirajući nam se tako kao dinamičan proces koji ipak nastoji zadržati jedinstvo i ravnotežu u danim društvenim okvirima. Naravno, to joj ne uspijeva uvijek i Vuk-Pavlović ukazuje na mogućnost da između

2007. O političkoj filozofiji koja stoji u pozadini ovih dviju rasprava usp. Tvrtko JOLIĆ, Zajednica i vrijednosti. Politika u djelu Pavla Vuk-Pavlovića, u: Sead Alić (ur.), Na Sjeveru s Pavlom Vuk-Pavlovićem. Zbornik radova s međunarodnog znanstvenog simpozija, Koprivnica, Sveučilište Sjever, 2018, 40-51.

${ }^{6}$ Vuk-Pavlović, Vrednota u svijetu..., 185.

7 Bronisław MALINOWSKI, Culture, u: Edwin R. A. Seligman (ur.), Encyclopedia of the Social Sciences, sv. 4, New York, Macmillan, 1931, 621-646.

${ }^{8}$ Studiju »Pogled na kulturnopovijesna smjeranja« Vuk-Pavlović je izložio 1958. godine na kongresu u Bolzanu, a prvi put je objavljena 1964. u Godišnjem zborniku Filozofskog fakulteta Univerziteta u Skopju i iste godine na njemačkom jeziku u časopisu Ricerche Filosofiche pod naslovom »Zur Gegenwartslage der europäischen Kultur«.

9 Roy D'ANDRADE, The Development of Cognitive Anthropology, Cambridge, Cambridge University Press, 2003, 12-13. 
kulture i životnih potreba čovjeka mogu nastati (pa i nastaju) mimoilaženja. To su situacije u kojima možemo govoriti o krizi, pri čemu valja imati na umu da ono što je u krizi može biti ili kultura ili sam život, a u nekim slučajevima i oboje. No Vuk-Pavloviću su u žarištu zanimanja načini na koje nesklad između kulture i potreba ljudskoga opstanka izaziva »neslućene sukobe i borbe u dosegu ljudskih odnosa«. ${ }^{10}$

Razloge za ove sukobe i borbe možemo naći upravo u unutrašnjim napetostima u samoj kulturi i one su okidač koji pokreće dinamičke procese i transformacije kulture. Upravo je slika na oprečnim usmjerenostima utemeljenih kulturnih napetosti ključna odrednica Vuk-Pavlovićeva shvaćanja kulturnih procesa a samim time i temeljni kamen njegove filozofije povijesti. Oprečna usmjerenja u odgovorima na bitna pitanja ljudskoga života i opstanka vuku kulturni proces - a time i povijest ljudskoga društva - sad na jednu, sad na drugu stranu. Štoviše, taj proces nije uređen tako da se neka epoha može posve odrediti karakteristikama jednog od oprečnih kulturnih usmjerenja. Iako se može ustvrditi da u nekim epohama jedno usmjerenje ima dominantu moć i ono je to koje određuje karakter te epohe, Vuk-Pavlović ističe da je i tada u pozadini djelatan oprečan kulturni tijek, »više ili manje pritajen, no jednako kulturno relevantan i povjesnotvoran $\ll^{11}$

\section{Pogled na kulturnopovijesna smjeranja}

Da bi slikovito prikazao povijesnu dinamiku, Vuk-Pavlović se koristi primjerom dvojnog ili dvostrukog njihala, tj. njihala na koje je zakačeno još jedno njihalo. Taj jednostavan fizikalni sustav često se u predavanjima iz fizike koristi kao primjer dinamičke kompleksnosti i kaotičnih procesa. ${ }^{12}$ Koristeći se ovom usporedbom Vuk-Pavlović napominje da joj je cilj isključivo ukazati na dinamičnost i dijalektičnost kulturnopovijesnog procesa. Njome se ne žele odbaciti ona viđenja filozofije povijesti koje se služe modelom uzvojnice, bilo silazne, koja sugerira povijesno propadanje čovjeka i društva, bilo uzlazne koja pak upućuje na njihov uspon. U tom je pogledu Vuk-Pavlovićeva slika dvojnog njihala prvenstveno, da tako kažemo, »mehanički« prikaz kulturnopovijesnog procesa, pri čemu ostaje otvoreno kako će taj proces biti vrednovan.

Iako su pokreti povijesnotvornog dvostrukog njihala iznimno složeni, teško predvidljivi pa na momente i kaotični, Vuk-Pavlović detektira dvije njegove komponente koje su pokretači tog iznimno dinamičnog procesa:

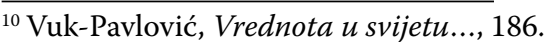

${ }^{11}$ Isto, 187.

${ }^{12}$ Richard LEVIEN, Sze TAN, Double pendulum. An experiment in chaos, American Journal of Physics, 61 (1993) 11, 1038-1044.
} 
»Te oprečne snage, prema kojima se kulturnopovijesni proces pričinja pokretom dvostruka ili dvojna njihala, [smije se] nazvati u smislu, a da se time ne izriče ocjena, s jedne strane snagom konzervativnom, a s druge revolucionarnom. $\ll^{13}$

Pa iako svaka od njih vuče na svoju stranu, obje su dio jedinstvene kulturne cjeline čija je putanja određena i obilježena unutarnjim oprekama i međusobnim napetostima ovih dviju komponenti. Može se stoga zaključiti da je kultura a time i povijest neke zajednice proizvod sukoba dvaju oprečnih nastojanja $u$ pokušaju da se odgovori na pitanje kako oblikovati i urediti ljudski život. ${ }^{14}$

Time što su ta oprečna nastojanja označena kao konzervativna i revolucionarna nismo dobili dublji uvid u sadržaj oko kojega se dolazi do napetosti između njih. Zato Vuk-Pavlović u nekoliko povijesnih epizoda iznosi primjere oko čega su se vodili sukobi koji su oblikovali, prije svega, europski kulturni prostor i povijest. Prvi i formativno najvažniji takav primjer je sukob vjere i znanja koji se začeo u antičkoj Grčkoj u kojemu s jedne strane stoje konzervativni zagovornici religijskih autoriteta, a s druge strane sofistički i filozofski revolucionari. U suptilnoj analizi dinamike sukoba između ovih dvaju kulturnih nastojanja, Vuk-Pavlović pokazuje da je kroz povijest ovog sukoba - od donošenja atenskog zakona protiv bezboštva 432. pr. Kr., preko helenističkog razdoblja, vremena ranoga kršćanstva i kasnijih epoha - bez obzira na trenutnu dominaciju jedne od tih struja, ona druga itekako latentno djelatna. Koliko god se u tim sukobima koristila i brutalna sila, čiju su oštricu osjetili kako zagovaratelji znanja tako i zagovornici vjere, sila nikada nije bila dovoljna da se bilo koje od sukobljenih kulturnih strujanja posve zatomi i iskorijeni. I kada u društvu dođe do pada uvjerljivosti vjerskih objašnjenja te ona znanstvena zadobiju dominaciju i mogućnost nasilna potiskivanja oprečnih strujanja, vjera često u potaji oblikuje nov skup objašnjenja koja daju odgovore na izazove pred koje ljude stavljaju nove društvene okolnosti. Sličnu dinamiku Vuk-Pavlović nalazi i u drugim svjetonazorskim sukobima koji su oblikovali našu kulturu i povijest, kao što su sukob između individualizma i kolektivizma ili s njim blisko povezan sukob zagovornika prvenstva ideje slobode i zagovornika prvenstva ideje jednakosti.

Zbog ograničenog prostora ovdje se neće ulaziti u detalje iznimno zanimljive Vuk-Pavlovićeve analize ovih filozofskih, političkih i ideoloških sukoba. Za svrhu ovoga rada vjerujem da će biti dovoljno istaknuti nekoliko ključnih momenata koji su, po mojem mišljenju, zajednički Vuk-Pavlovićevoj analizi dinamike europskih kulturnopovijesnih procesa. Prvi ključan moment u Vuk-

\footnotetext{
${ }^{13}$ Vuk-Pavlović, Vrednota u svijetu..., 187.

${ }^{14}$ Sličnu dinamiku povijesnog procesa uočava i Wilhelm Dilthey koji u svojoj Izgradnji duhovnog svijeta u humanističkim znanostima piše sljedeće: »Pored opće, dominantne i sveprožimajuće tendencije koja obilježava neko vrijeme, postoje i druge tendencije koje su joj oprečne. One streme konzervirati ono staro, promatraju negativne posljedice jednostranosti duha vremena i okreću se protiv njega « (usp. Wilhelm DILTHEY, Gesammelte Schriften, sv. VII. Der Aufbau der geschichtlichen Welt in den Geisteswissenschaften, 4, nepr. izd., Stuttgart, B. G. Teubner Verlagsgesellschaft, Vandenhoeck \& Ruprecht in Göttingen, 1965, 178).
} 
Pavlovićevoj filozofiji povijesti jest svakako već spomenuti dijalektički karakter kulturnopovijesnih procesa. Njegova analiza pokazuje da povijest nikada ne staje, da nema kraja, u smislu da bi jedno kulturno usmjerenje moglo zadobiti takvu dominaciju da postane definitivni, konačni obrazac uređenja društva. Postoje samo stabilnija razdoblja u kojima je dominantan jedan od konkurentnih kulturnih svjetonazora, no nakon ovih stabilnijih razdoblja slijedi kriza kulture izazvana jačanjem konkurentnih svjetonazora i slabljenjem kulturne jezgre, one koja kulturi daje jedinstvo i kontinuitet. ${ }^{15}$

Iz ovoga shvaćanja proizlazi drugi, možda i važniji moment Vuk-Pavlovićeve filozofije povijesti, onaj koji se tiče pitanja naravi promjene između dominantnih i latentnih oprečnih uvjerenja koja su u međusobnoj protimbi. Ta se promjena ne događa bez lomova i žrtava, te se može reći da je prisila ključan moment $\mathrm{u}$ tom procesu. $\mathrm{O}$ naravi kulturnopovijesnih procesa i njihovih mijena najdojmljivije govore termini koje Vuk-Pavlović koristi u svojoj analizi. U kontekstu dijalektike između oprečnih stajališta to su prije svega »nasilje«, »potiskivanje«, »dominacija«, »sukob« i »borba«. Evo jednog tipičnog citata: »Kulturni proces pri tako izazvanim obratima i preokretima opet i opet traži žrtve i gotovo bez izuzetka izaziva gdjekad i blažu, no ponajčešće žešću, pa i nečovječnu borbu«. ${ }^{16}$ Sukob ne nastaje samo u slučajevima revolucionarnih prevrata kada jedan svjetonazor zamjenjuje drugi, već i onda kada se pokušava uspostaviti kulturno jedinstvo. Element nasilja i prisile postoji tako vrlo često i u samom činu formiranja kulture, ali i kasnije u nastojanjima da se ona učvrsti i perpetuira. Intenzitet prisile nije naravno uvijek isti: on seže od nasilnog progona i zatiranja kako pojedinaca tako i cijelih skupina pa do posve blagih oblika prisile koje često ni ne percipiramo kao oblike nasilja, kao što su primjerice vjerska indoktrinacija ili obrazovni procesi kojima se od strane vlasti usađuju neki kulturni sadržaji.

$\mathrm{Na}$ temelju Vuk-Pavlovićeve usporedbe povijesnih procesa s dvostrukim njihalom, za koje smo rekli da se u fizici može koristiti kao primjer kaotičnih procesa, netko bi mogao reći da Vuk-Pavlović niječe uređenost povijesti prema nekom obrascu. Ako analogiju s njihalom uzmemo ozbiljno, onda odmah treba ustvrditi da je kaos u slučaju dvostrukog njihala deterministički kaos i da se položaj i putanja njihala, koliko god izgledala složena i naoko nepredvidiva, ipak može utvrditi primjenom matematičke formule ako su poznate sve početne varijable. Primjenom te analogije na povijesne procese i oni se pokazuju kao uređena i racionalno spoznatljiva cjelina. Nevolja s determinističkim kaosom jest ta da nam u većini slučajeva početno stanje sustava nije poznato, a i minijaturne razlike u početnom stanju mogu se kasnije razviti do znatnih razlika. ${ }^{17} \mathrm{Iz}$

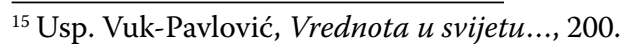

${ }^{16}$ Isto, 195.

${ }^{17}$ Usp. Edward N. LORENZ, Deterministic nonperiodic flow, Journal of the Atmospheric Sciences, 20 (1963) 130-141.
} 
toga je razloga u svim takvim složenim sustavima na temelju nepreciznih podataka teško i praktički nemoguće sa sigurnošću utvrditi kako će se sustav dalje razvijati. Povijesni procesi su također iznimno kompleksni i teško da se mogu svesti na mehaničku razinu. S obzirom da ti procesi bitno određeni ljudskim djelovanjem, može se reći i da su mnogo složeniji od prirodnih procesa kojima se inače bavi teorija kaosa. Uzimajući u obzir svu ovu složenost, Vuk-Pavlovićeva analogija s dvostrukim njihalom ipak prepoznaje pravilnosti u mijenama i obratima koji nam omogućavaju uvidjeti povezanost povijesnih procesa i događaja koji ih obilježavaju, iako to naravno ne znači da možemo predvidjeti kako će se povijest dalje odvijati.

Ovime naravno ne želim implicirati da Vuk-Pavlović pretpostavlja da se povijesni procesi daju analizirati istim metodama kao što se analiziraju procesi $\mathrm{u}$ prirodnim znanostima. Nekoliko je razloga zašto je to tako. Prije svega $u$ Vuk-Pavlovićevoj analizi povijesnih procesa posve nedostaje pojam uzroka koji je temeljni objasnidbeni model u prirodnim znanostima. Zašto dolazi do promjena u kulturi i povijesti, zašto dominantni nazor slabi i u konačnici ga zamjenjuje oprečni nazor, nećemo razumjeti nekom kauzalnom analizom, već razumijevanjem konkretnih okolnosti u kojima je nastala promjena. Već i samo Vuk-Pavlovićevo inzistiranje da se njegovi uvidi odnose na europski kulturni krug, ostavljaju otvorenim pitanjem kako stvari stoje s drugim kulturama i jesu li se povijesni procesi u njima odvijali prema drugačijim obrascima. Drugi razlog koji naše razumijevanje povijesti odvaja od razumijevanja prirode jest i vrijednosna dimenzija kulture. Iako Vuk-Pavlović u svojoj analizi uvažava i pozitivno vrednuje svako od oprečnih kulturnih nastojanja, on jasno daje do znanje da kriza nastaje onda kada dominantna strujanja unutar kulture zanemare ono što je najvažnija zadaća kulture, a to je omogućavanje da čovjek nesmetano razvije svoje najvažnije potencijale. Ti potencijali za Vuk-Pavlovića leže u duhovnoj dimenziji čovjeka, pa stoga ona nastojanja koja čovjeka shvaćaju samo kao biološko, prirodno biće završavaju u slijepoj ulici i osuđena su na uvijek nov neuspjeh i konačan slom. ${ }^{18}$

\section{Značenje povijesne predaje}

Ponovni pokušaj sustavnijeg pristupa razumijevanju povijesti Vuk-Pavlović poduzima u ogledu »Značenje povijesne predaje«. Za razliku od »Pogleda na kulturno povijesna smjeranja u $u$ kojemu filozofiji povijesti pristupa pokušavajući utvrditi obrazac povijesnog procesa, on ovdje razmatra ulogu koju povijest ima u oblikovanju svijeta u kojemu živimo te način na koji čovjek stoji u odnosu prema povijesti. Naspram shvaćanja povijesti kao objektivne danosti

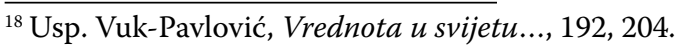


koja je egzaktno znanstveno utvrdiva, Vuk-Pavlović ovdje naglasak stavlja na važnost subjektivno življene povijesti. Razumljivo je da je za svaki povijesni pristup nužno utvrditi temeljne činjenice, kao što su vrijeme u kojemu se nešto dogodilo, aktere koji su tom događaju sudjelovali kao i vjerojatne uzroke koji su tome prethodili i učinke koji su uslijedili. Međutim, povijesno značenje za VukPavlovića imaju samo ona događanja koja nisu »tek u objektivnom smislu socijalno značajna, nego su istinski i subjektivno živa.$^{19}$ A neki povijesni događaj je »istinski i subjektivno živ« utoliko što je karika u lancu koja povezuje prošla pokoljenja sa sadašnjim i budućim pokoljenjima. Ta povijesna spona nema svoj smisao samo za pojedince, već se prije svega njen smisao otkriva u društvenom kontekstu u kojemu pojedince iz različitih generacija spaja $\mathrm{u}$ »oduhovljeno sudbinsko jedinstvo«.

Uzimajući u obzir ovaj drugi pristup filozofiji povijesti, Vuk-Pavlović ne niječe mogućnost objektivnog spoznavanja povijesti. Takav znanstveni pristup nama je dostupan, podvrgnut je standardnim ograničenjima ljudskoga spoznavanja, no na taj način shvaćena povijest za njega ne mora biti nužno i »živa povijesnost«. Povijesni značaj nekoga događaja za Vuk-Pavlovića je uvijek relativan, i to ne u odnosu na stajalište nekoga pojedinca, već u odnosu prema »zbiljskoj socijalnoj skupini« koja stoji u nekom bitnom odnosu prema tome povijesnom događaju. Ta skupina, prepoznajući u povijesnim događajima odrednice koje oblikuju njenu sudbinu, na njihovim temeljima izgrađuje tradiciju ili predaju koja tu povijesnost čini živom i bitnom za život i održanje te skupine. Stoga, za Vuk-Pavlovića, sami događaji kao objektivne danosti ne postaju dio povijesti i predaje na izravan način, samim time što su se dogodili, već je nužno da oni na stanovit način budu doživljeni od strane čovjeka. U slučaju povijesne predaje taj ljudski doživljaj nikada nije temeljen na bezinteresnom stavu pojedinca kojemu je cilj prikupiti objektivno dane činjenice. $\mathrm{Za}$ Vuk-Pavlovića to je »silovita, živa pokretna snaga« usmjerena na oblikovanje i izgradnju života u zajednici. ${ }^{20}$ Najvažnija manifestacija zajednice kao sudbinskog jedinstva za njega je narod, pripadnost kojemu omogućava pojedincu da osigura trajanje i prijenos kulturnih, moralnih i političkih dobara i vrijednosti mimo ograničenja individualne egzistencije.

Povijesna je predaja temelj za izgradnju nacionalne zajednice te Vuk-Pavlović smatra da je ona puno važnija za njeno održanje no što su to druge odrednice nacionalnog bića, kao npr. vjera, jezik ili državne institucije. ${ }^{21}$ Utoliko je težnja svakog naroda da posjeduje, održava i razvija svoju povijesnu predaju od iznimne političke i društvene važnosti pa se s pravom može zahtijevati da se »narodi i njihove vlasti s obzirom na to pridržavaju bezuvjetne tolerancije, da

\footnotetext{
${ }^{19}$ Vuk-Pavlović, Vrednota u svijetu..., 207.

${ }^{20}$ Usp. isto, 211.

${ }^{21}$ Usp. isto, 214-215.
} 
gaje stalnu međupredajnu snošljivost . $^{22}$ No pozivanjem na toleranciju spram različitih povijesnih narativa, ukazuje se na neuralgičnu točku Vuk-Pavlovićeva, ali i svakog drugog subjektivističkog shvaćanja povijesti. Kako naime u tom okviru pomiriti potencijalno proturječne i sukobljene interpretacije povijesnih događaja; slavna ratna pobjeda jedne strane u sukobu je istodobno zločinački masakr za drugu stranu, heroji pobjednika zločinci su poraženih? No za sukobe oko interpretacije povijesnih događaja nije potrebno gledati samo međunarodne odnose, one su moguće i unutar naroda samoga. O takvim unutarkulturnim napetostima kao uzrocima sukoba i krize kulture govorili smo već u ovom tekstu.

Ne bi li se ovakve sukobe oko različitih interpretacija povijesti moglo riješiti posezanjem za znanstvenim pristupom povijesti kojim bi se nepristrano i objektivno utvrdilo sve relevantne činjenice i okolnosti povijesnih događaja? Za Vuk-Pavlovića to nije izgledan put jer povod neslaganja i sukoba nisu nesporazumi oko činjenica, već su oni znatno češći i snažniji oko interpretacije tih činjenica, pri čemu se napušta domena deskriptivne znanosti i ulazi u domenu vrijednosti. Povijesna predaje dio je svijeta vrijednosti u kojemu čovjek živi, ona mu daje oslonac i uputa za djelovanje, ali povijesna predaja nije i ne može biti krajnji kriterij prosudbe naših djelovanja. Za Vuk-Pavlovića

»ispred povijesne svijesti i iznad nje, a tako i iznad smjernica i pobuda same povijesne predaje ima još viši i zapovjedniji zakon. A taj zakon nije zakon povijesti ni zakon predaje, već zakon s najviše prečage vrijednosne ljestvice, zakon nad zakonima, zakon ćudorednosti. ${ }^{23}$

Vuk-Pavlović prihvaća da je naš kulturni i društveni svijet ustrojen tako da različite tradicije utemeljene na zasebnim povijesnim predajama dijele ljude, no pozivajući se na univerzalni etički kodeks zajednički svim ljudima, on ukazuje na nužan korektiv bez kojega bi te podjele bile prijetnja ljudskom suživotu i opstanku.

\section{Zaključak}

U svojim ogledima Vuk-Pavlović razmatra na koje je sve načine naš životni svijet oblikovan kulturom i poviješću, te ukazuje da je, ako ga se hoće razumjeti, nužno proniknuti u dinamiku kulturnopovijesnih procesa kao i u važnost tih dvaju fenomena za život zajednice. U duhu spekulativnih pristupa filozofiji povijesti on istražuje moguće pravilnosti u povijesnom razvitku, da bi ustvrdio da samo promjena stalna jest. No to nije isprazan zaključak, jer njegova nam analiza otkriva postojanje stalnih napetosti unutar svake zajednice, a

\footnotetext{
${ }^{22}$ Isto, 216.

${ }^{23}$ Isto, 221.
} 
koje su katalizator kulturne promjene. Te napetosti obilježavaju sve najvažnije segmente kulture neke zajednice i sukobi se najčešće vode, barem u našem zapadoeuropskom kulturnom krugu, oko odnosa vjere i znanja u društvu, uloge pojedinca i kolektiva i važnosti slobode i jednakosti za uređenje društva.

Drugi smjer Vuk-Pavlovićeva istraživanja filozofije povijesti osvjetljava ulogu koju povijest, kako nam je dana u povijesnoj predaji, ima u našim životima. Ispostavlja se da je ona osnova za uspostavljanje i održanje sudbinskih zajednica, naroda. U tim sudbinskim zajednicama povijesna predaje »živi«, ona se prihvaća, mijenja i nadopunjuje ali, ponekad, odbija i odbacuje. ${ }^{24}$ Vuk-Pavloviću je stalo naglasiti da povijesna predaja svoju ulogu ne može ispuniti ako je ona samo egzaktan, empirijski utvrđen niz povijesnih događaja. Za povijesnu predaju od odlučujuće je važnosti da bude živa, to jest da bude potporni stup na kojemu počiva život u zajednici. No, svjestan mogućnosti da zloporaba povijesne predaje dovede do izopačenih pojava koje mogu ugroziti budućnost budućih pokoljenja, Vuk-Pavlović inzistira da etički kriteriju uvijek moraju biti krajnja instanca koja je mjerodavna za ljudsko djelovanje.

Na temelju ovih razmatranja ne može se tvrditi da je Vuk-Pavloviću imao za cilj izložiti sustavno razrađenu teoriju povijesti. Prvenstveni cilj ovih njegovih dvaju ogleda koje se ovdje razmotrilo, jest da u njima iznese bitne uvide u neke od elemenata dinamike povijesnog procesa i značenja povijesti za naš današnji, suvremeni život. Vuk-Pavloviću je u ovim ogledima stalo, kao što ističe Videnović, da ukaže na opasnost da oprečne kulturne tendencije rastoče jedinstvo i cjelovitost kulture. ${ }^{25}$ Iako su pristupi koje primjenjuje $u$ analiziranju fenomena povijesti različiti, Vuk-Pavlović u oba ogleda uočava da svijet u kojemu živimo suočen s dubokim protimbama i sukobima. Bez obzira je li riječ o sukobu oko vjere i znanja, slobode i jednakosti, ili pak oko interpretacije povijesnih događaja, jačina sukoba i posebno brojnost razdjelnica po kojima se društvo cijepa dovode do duhovne krize. Takva je kriza naročito izgledna u situacijama u kojima ne postoji »međusobna snošljivost« među sukobljenim stranama. ${ }^{26}$ Vuk-Pavlović ne dvoji da su jedinstvo i cjelovitost društva potrebni da bi zajednica funkcionirala i da bi mogla odgovoriti na izazove koji se postavljaju pred njene članove. Ostajući vjeran svojim temeljnim filozofskim uvjerenjima, Vuk-Pavlović to jedinstvo nalazi u poštovanju univerzalnog etičkog zakona koji nam između ostaloga propisuje i odgovornost prema budućim naraštajima, ali i u vjeri u transcendentno.

\footnotetext{
${ }^{24}$ Usp. isto, 209.

${ }^{25}$ Usp. Videnović, Aktualnost filosofije povijesti..., 110.

${ }^{26} \mathrm{O}$ Vuk-Pavlovićevim stavovima o toleranciji kao i o granicama tolerancije usp. Milan POLIĆ, Paradoks tolerancije - Vuk-Pavlović prije Poppera, Prilozi za istraživanje hrvatske filozofske baštine, 24 (1998) 1-2, 185-194.
} 
Tvrtko Jolić:

The Double Pendulum of History. Vuk-Pavlović's Philosophy of History

Summary

Vuk-Pavlović's philosophy of history is closely connected with his conception of culture as a dynamical process in which historical epochs alternate depending on the strength of conflicting worldviews. By taking in consideration examples of the conflicted worldviews (nominalism vs realism, individualism vs collectivism, freedom vs equality), we will try to reach a closer understanding of historical processes as understood by Vuk-Pavlović. The paper also discusses the role that Vuk-Pavlović attributes to the history in the shaping of the social life. Although it cannot be said that Vuk-Pavlović presented all details of his philosophy of history, the paper shows that his assumptions about the nature of historical processes and man's relationship to history provide a basis for a deeper understanding of dynamics within contemporary political communities.

Key words: culture, history, Pavao Vuk-Pavlović, philosophy of history, philosophy of culture.

(na engl. prev. Tvrtko Jolić)

\footnotetext{
* Tvrtko Jolić, PhD, Assis. Prof., Institute of Philosophy; Address: Ulica grada Vukovara 54, HR-10000 Zagreb, Croatia; E-mail: tjolic@ifzg.hr.
} 